\title{
ESPACIOS DRAMÁTICOS EN ROJAS ZORRILLA
}

\author{
ANA SUÁREZ MiRAMÓN
}

UNED

\section{RESUMEN}

El espacio resulta fundamental en el teatro y Rojas utiliza con gran habilidad tanto los espacios abiertos como los cerrados. Incluso alterna unos y otros y los acompaña del contraste entre luz y oscuridad para intensificar la tensión dramática. Un examen detenido de la función del espacio en Lo que quería ver el marqués de Villena y Casarse por vengarse, muestra la importancia del espacio para la acción, para transmitir estados emocionales, situaciones dramáticas e incluso representar la teatralidad. de Oro.

Palabras clave: Temas en la literatura, obra literaria de Rojas Zorrilla, teatro de la Edad

\section{ABSTRACT}

Space is a fundamental element in theatre and Rojas uses both open and closed spaces with a great ability. He even alternates one and other, open and closed spaces, and includes light and darkness' contrast in order to intensify the dramatic tension. A detailed analysis of the function of space in Lo que quería ver el marqués de Villena and Casarse por vengarse, shows the important role that space plays in the development of action, in the transmission of emotional feelings or dramatic situations, and even in the representation of theatrical features.

Key words: Literary themes, Rojas Zorrilla's works, Golden Age's theatre.

No hay duda de que en el teatro el espacio constituye un elemento fundamental de la obra dramática puesto que es la base en la que se apoya su construcción. Sólo a partir de él se desarrolla la acción, evoluciona el personaje y tiene lugar la trama. Todo cuanto acontece en el orden físico, moral y sentimental se produce y se experimenta en un determinado espacio. Como afirmó A. Ubersfeld, de los diversos géneros literarios existentes solo el teatro «necesita, para existir, de un lugar, de una espacialidad donde desplegar las relaciones físicas entre los personajes» ${ }^{1} \mathrm{y}$, por consiguiente, dicho espacio se inserta en el contexto cultural de la época en que se produce la obra y puede fácilmente adquirir una serie de relaciones más

1 Ubersfeld, Semiótica teatral, Madrid-Murcia, Cátedra-Universidad de Murcia, 1989, p. 108. 
o menos intensas hasta alcanzar un posible carácter alegórico o simbólico en cuanto se adapta, identifica o coincide (por tradición) con determinados estados de ánimo, acciones, condiciones morales o emociones, como ocurre en el mundo barroco. Puesto que, además, ya desde la Escuela de Praga, en que se plantearon las relaciones entre texto y literatura y se establecieron las bases para el estudio diferenciado entre el texto y la representación, la semiología concretó la dualidad de ambas posibilidades, siempre obligatoriamente presentes en una obra representada. Las diferencias entre espacio teatral y espacio dramático fueron claramente definidas por Pavis ${ }^{2}$, a partir de las teorías semióticas de Lotman y Ubersfeld y, en general, han sido seguidas por la mayoría de críticos. Sus conclusiones fueron, como afirma Arellano ${ }^{3}$, excelentemente aplicadas primeramente por $\mathrm{Vitse}^{4}$ a $\mathrm{La}$ dama duende de Calderón y han servido para orientar multitud de trabajos en los últimos años, y para indagar en la historia del escenario barroco en sus dos modalidades: texto y espectáculo. De este modo, con investigaciones paralelas se ha aportado una visión más completa sobre las posibles soluciones que este teatro llevó a cabo para representar los espacios escénicos, de acuerdo con las diferentes formas del teatro de la época. Los trabajos de Regueiro ${ }^{5}$ y García Barrientos ${ }^{6}$, sobre todo, contienen una amplia información bibliográfica sobre este problema lo cual nos exime de insistir ahora en esa dualidad teatral puesto que ya son muy numerosas las reuniones científicas dedicadas al problema en sus dos dimensiones, teórica y práctica. Asimismo, la publicación de libros colectivos o recopilatorios sobre el tema, tanto en su aspecto textual ${ }^{7}$ como de investigación sobre los esce-

${ }^{2}$ Diccionario del teatro: dramaturgia, estética, semiología, Barcelona, Paidos, comunicación [1980], 1990, pp. 179-184.

3 «Espacios dramáticos en los dramas de Calderón», en El escenario cósmico. Estudios sobre la comedia en Calderón, Universidad de Navarra, Iberoamericana Vervuert, Madrid, 2006, pp. 69-92.

${ }^{4}$ El trabajo «Sobre los espacios en La dama duende: el cuarto de don Manuel» (Notas y Estudios filológicos, 2, pp. 7-32) apareció por primera vez en 1985. Posteriormente ha sido reproducido en RILCE, 12, 2 (1996), pp. 337-356, y en Cuadernos de Teatro Clásico, 15 (2001), pp. 141-160. Puede verse en la «loa de apertura»al Homenaje a F. Serralta, la anécdota sobre el tema, recordada por el propio M. Vitse en torno a la importancia de los espacios teatrales (Homenaje a Fréderic Serralta. El espacio y sus representaciones en el teatro español del Siglo de Oro. Actas del VII Coloquio del GESTE, celebrado en Toulouse, 1-3 abril,1998, ed. Françoise Cazal, Christophe González y Marc Vitse, Universidad de Navarra, Iberoamericana Vervuert, Madrid, 2002, pp. 22-24.

5 Espacios dramáticos en el teatro español medieval, renacentista y barroco, Kassel, Reichenberger, 1996

${ }^{6}$ Espacialmente está analizada la teoría sobre el espacio en Cómo se comenta una obra de teatro, Madrid, Síntesis, 2001, pp. 121-152.

7 Por citar algunos representativos, Homenaje a Fréderic Serralta. El espacio y sus representaciones en el teatro español del Siglo de Oro. Actas del VII Coloquio del GESTE, celebrado en Toulouse, 1-3 abril, 1998 (ed. Françoise Cazal, Christophe Gon- 
narios, llevadas a cabo, sobre todo por Varey y Ruano de la Haza, han abierto un camino de gran interés para entender la obra teatral barroca en cuanto texto y espectáculo perfectamente construido por los autores.

En el caso concreto de Rojas Zorrilla, ya González Cañal se ha ocupado de la creación y manejo de los espacios dramáticos domésticos en las comedias de capa y espada y en los espacios apropiados para crear enredos así como el interés por los espacios contiguos ${ }^{8}$ (muy frecuentes también en Calderón y en Tirso). Ante todo hay que recordar que Rojas, como discípulo y colaborador de Calderón, debía conocer perfectamente el impacto dramático que determinados ámbitos espaciales tenían sobre la escena, tanto en la tragedia ${ }^{9}$ como en los dramas o autos ${ }^{10}$. Desde luego, los juegos espaciales que exhibe en algunas de sus obras nos muestran una gran habilidad para oponer espacios y añadir incluso un contraste temporal y cromático que intensifica esa oposición, pese a que en su obra, a diferencia de la de Calderón, mostró una original preferencia por utilizar medios y técnicas propios de los corrales de comedias, como ya destacó F.

zález y Marc Vitse), Universidad de Navarra, Iberoamericana Vervuert, Madrid, 2002; Texto, espacio y movimiento en el teatro del Siglo de Oro, ed. de Aurelio González, México, El Colegio de México, 2000; Espacio, tiempo y género en la comedia española. Actas de las II Jornadas de Teatro clásico celebradas en Toledo, 14-16 noviembre 2003 (ed. de F. Pedraza, R. González Cañal y Gemma Gómez), Almagro, Universidad de Castilla-La Mancha, 2005; Loca ficta: los espacios de la maravilla en la Edad media y Siglo de Oro, ed. de I. Arellano, Universidad de Navarra. Iberoamericana, Vervuert, Madrid, 2003; Escenografía y escenificación en el teatro español del Siglo de Oro. Actas del II Curso sobre teoría y práctica del teatro, organizado por el Aula Mira de Amescua y el Centro de Formación Continua, celebrado en Granada, 10-13 noviembre, 2004 (ed. R. Castilla y M. González Denigra), Granada, Universidad, 2005, y el más reciente, de I. Arellano, El escenario cósmico. Estudios sobre la comedia en Calderón, Universidad de Navarra, Iberoamericana Vervuert, Madrid, 2006. Todos ellos incorporan una amplia bibliografía.

${ }^{8}$ R. GONZÁLEZ CAÑAL, «El espacio escénico en las comedias de capa y espada de Rojas Zorrilla», Escenografía y escenificación en el teatro español del Siglo de Oro. Actas del II Curso sobre teoría y práctica del teatro, organizado por el Aula Biblioteca Mira de Amescua y el Centro de Formación Continua, celebrado en Granada (10-13 noviembre, 2004), ed. R Castilla y M. González Dengra, Universidad de Granada, 2005, pp. 169-199 y «Recursos espaciales del enredo en Rojas Zorrilla», Espacio, tiempo y género en la comedia española. Actas de la II Jornadas de teatro Clásico (Toledo, 1416 de noviembre, 2003), ed. de F. Pedraza, R. González Cañal y Gemma Gómez, Universidad de Castilla-La Mancha, Almagro, 2005, pp. 171-191.

9 Ver M. F. DÉDAT-KeSSEDJIAN, «Espacio, personaje y acción. La funcionalidad del espacio dramático en la tragedia calderoniana», Homenaje a F. Serralta, op. cit., pp. 190-208.

10 Arellano, «Espacios dramáticos en los dramas de Calderón», en El escenario cósmico. Estudios sobre la comedia en Calderón, Universidad de Navarra, Iberoamericana Vervuert, Madrid, 2006, pp. 69-92; «Espacios dramáticos en los autos de Calderón», Estructuras dramáticas y alegóricas en los autos de Calderón, Pamplona- Kassel, Universidad de Navarra-Edition Reichenberger, 2001, pp. 147-193. 
Pedraza ${ }^{11}$, aunque se tratase de comedias palatinas o tragedias de tema mitológico o de historia antigua, como estudió M. Trambaioli ${ }^{12}$.

Sin embargo, la considerada, con toda razón, obsesión de Rojas por las escenas nocturnas (por otra parte contrarias a las posibilidades representativas del corral) ha hecho pensar a Pedraza en que «esta inclinación de Rojas por los ambientes nocturnos obedece, entre otras razones, al gusto por lo insólito, por lo extravagante, por la dificultad que ha de ser vencida con las armas del ingenio y la palabra poética» y lo justifica como «un decorado verbal que no solo ha de sugerir lo inexistente (un castillo, un monte, la extensa planicie del mar), sino que ha de contradecir los datos irrebatibles de los sentidos» ${ }^{13}$ en cuanto que el espectador contemplaba siempre un escenario con luz. Para Pedraza, esa preferencia ha de enmarcarse en la importancia del oído que va guiando al espectador de Rojas como si se tratase de una auténtica «luminotecnia verbal». Desde luego, si la palabra es fundamental en el teatro barroco, pues ya Góngora multiplicó la capacidad de sugerir, reunir contenidos, mostrar colores, abrir espacios distantes, Rojas tuvo como modelo directo el teatro de Calderón en donde la palabra y el silencio capacitaban a los personajes para abrir nuevos recursos metateatrales y él no lo desaprovechó. Con esa luz para los oídos de la que nos habla Pedraza, Rojas consigue iluminar los espacios dramáticos y jugar con todo tipo de lugares para ofrecernos una obra singular a partir de topoi ya asentados por la tradición y reiterados sobre todo en las comedias.

En cuanto a la preferencia por los nocturnos, hemos de añadir la coincidencia de Rojas con Calderón que, fundamentalmente en los autos como síntesis del resto de su obra, utilizó de manera extraordinaria, como ya estudiamos en otro lugar ${ }^{14}$, y cuyo origen habría que buscarlo (con independencia de lo religioso en el caso de los autos) en la evidente simbología platónica, popularizada por la tradición, en el arte del claroscuro, en el hermetismo y en toda la imaginería iconográfica y emblemática que el teatro aprovechó extraordinariamente. Basta recordar la importancia de las artes

${ }^{11}$ F. PEDRAZA, «Rojas Zorrilla: un teatro para los oídos», Escenografía y escenificación en el teatro español del Siglo de Oro, op. cit., pp. 403-421.

12 M. TRAmbaioli, «Los encantos de Medea, de Rojas Zorrilla y la espectacularidad de la comedia de tramoya», Bulletin of the comediantes (1995), XLVII, pp. 275-294, y «Una obra mitológica de corral: Progne y Filomena de Rojas Zorilla», La década de oro de la comedia española: 1630-1640. Actas de las XIX Jornadas de teatro clásico de Almagro (julio, 1996), Universidad de Castilla-La Mancha, Festival de Almagro, 1997, pp. 263-280.

${ }^{13}$ F. PEDRAZA, «Rojas Zorrilla: un teatro para los oídos», Escenografía y escenificación en el teatro español del Siglo de Oro, op. cit. pp. 405-406.

14 «Los espacios nocturnos en el auto sacramental de Calderón», La dramaturgia de Calderón: técnicas y estructuras, I. Arellano y E. Cancellieri (eds), Madrid-Frankfurt, Iberoamericana/ Vervuert, 2006, pp. 519-540. 
visuales en el teatro y la necesaria traslación en palabras de esas imágenes, que circulaban en las recopilaciones de Athanasius Kircher ${ }^{15}$, por ejemplo, como la cámara oscura y la linterna mágica para proyectar imágenes pintadas sobre vidrio (experimentos realizados antes por de G. de la Porta, físico conocido por Calderón ${ }^{16}$ ), que debían constituir un aliciente para el teatro, tanto en su aspecto escenotécnico como en el simbólico textual. Esa preferencia por la noche creemos que debe relacionarse con el propio sentido teatral en cuanto dimensión fantástica y parte del proceso dramático, ya que permite considerar el escenario como un teatro cuya escenificación (segunda) puede aparecer en cualquier momento, lo cual incrementa la tensión. Además, en Rojas, se dan con mucha frecuencia metateatros que, por contraste, se muestran plenos de luz en un ejercicio de ticoscopia que, al tiempo que recuperan la actualidad del pasado, explican y justifican los comportamientos de los personajes. La preferencia del autor por la diégesis en temas relacionados con el amor y la belleza tiene, a su vez, una estrecha relación con la pintura y así en los nuevos espacios la presentación, muy frecuente en el autor, de una bañista desnuda o mujer cerca del agua (presentación que siempre es lenta, va precedida de verbos dicendi y consigue crear otro juego de tensiones, e incluso otro espacio dramático en donde el protagonista puede observar, como un espectador del segundo teatro, sin ser visto), le sirve para ponderar la luz y el dinamismo. El resultado es una auténtica pintura que puede sugerir (siempre por la palabra) un espacio dramático invisible para el espectador pero vivo en su imaginación. En algunos casos, el propio personaje se refiere a la pintura, como en No hay amigo para amigo. Como normalmente se corresponde con el monólogo de un personaje que está situado estratégicamente al principio de la primera o segunda jornada, su importancia es fundamental. Con esta técnica de flash-back se consigue, además de informar, contrastar y oponer la ilusión con la realidad, en perfecta imitación, en otro orden, de las viejas cosmogonías que muestran el dualismo de la existencia. Así, la luz y la nocturnidad se corresponde igualmente con la oposición de espacios abiertos y cerrados (naturaleza-casa o calle) tan predilecta por el autor. A su vez, tanto en los espacios abiertos como en los cerrados se produce una alternancia, a veces con grandes contrastes, entre la gruta y el palacio en Los áspides de Cleopatra (intensificada por la oposición entre palacio y quinta y monte y prado), Persiles y Sigismunda, Los bandos de Verona y Los celos de Rodamonte; la cueva y casa urbana en Lo que quería ver el marqués de Villena; el palacio y la quinta en Progne y Filomena, Casarse por vengarse y Peligrar en los remedios y, desde luego, la oposición más

15 A. Kircher, Ars magna lucis et umbrae (ed. facsimilar de 1671, Santiago de Compostela, Universidad, 2000) y Mundus subterraneus (Ámsterdam, Rodopi, 1978).

${ }^{16}$ Citado en El astrólogo fingido. 
frecuente, cuando predomina un espacio urbano, como la casa o el palacio (de acuerdo con los protagonistas), en donde se alterna lo abierto y cerrado, representado por puertas, llamadas, llaves, e incluso tabiques abiertos (Casarse por vengarse), balcones tapiados (Sin honra no hay amistad) o puertas cerradas que se intentan forzar (Donde hay agravios) o que se ignora si están abiertas o cerradas (Los celos de Rodamonte). En los espacios cerrados crece la tensión (Sin honra no hay amistad, No hay padre siendo rey, La traición busca el castigo, Casarse por vengarse), al igual que con la nocturnidad, mientras que los espacios abiertos, en general, traducen las ilusiones o el mundo interior.

Entre los espacios abiertos, el que menos presencia tiene es el monte o selva (Los áspides de Cleopatra) y el que más, el jardín o el más amplio, el prado. El jardín, que en sí mismo tiene el valor inmanente de la dualidad (bien y mal; belleza y fealdad; placer y dolor; luz y sombra; vida y muerte; estancia femenina y espacio de violación) aparece con frecuencia. Unas veces, de día, formando una verdadero cuadro de luz, propio de la ilusión (No hay amigo para amigo, Sin honra no hay amistad); otras, de noche, expresando la caída de la mujer o su violación (Los áspides de Cleopatra, Donde hay agravios no hay celos, Progne y Filomena) y, en bastantes ocasiones, afianzando la confusión (No hay padre siendo rey, Obligados y ofendidos, El más impropio verdugo, Sin honra no hay amistad), o manifestando la categoría de los personajes (Persiles y Sigismunda), pero siempre resaltando la belleza sin olvidar la oposición innata. Incluso con el valor religioso de los jardines medievales y simbólicos se muestra en Santa Isabel. El prado, espacio más amplio y frondoso, en donde el agua siempre se hace presente con una finalidad pictórica, teatral y dramática, representa el alma (Peligrar en los remedios) y la ilusión, pues, como se afirma en El falso profeta Mahoma «todo de prodigios lleno». El agua intensifica la luz de la atmósfera abierta para constituir una verdadera visión, intensificada por la hora del mediodía, del amanecer, o incluso del atardecer, cuando aún tiene gran fuerza el sol. Es el tiempo siempre elegido, además de las estaciones de la primavera o verano («era del día la estación ardiente») como propio del encuentro y de la exaltación amorosa (Entre bobos anda el juego, No hay amigo, Casarse por vengarse, Los áspides de Cleopatra, Lo que quería ver el marqués de Villena, Peligrar en los remedios, No hay padre siendo rey, El más impropio verdugo). Solamente en Los encantos de Medea, esa luz resulta un engaño y lo que parece un ameno prado resulta ser una selva «lóbrega y oscura» como corresponde al falso palacio de Medea. A veces, ese prado adquiere un tono trágico en donde también desaparece la luz en favor del color rojo, como en Persiles y Sigismunda.

Hay algunas obras de Rojas muy representativas de esa preferencia por la alternancia de espacios, la nocturnidad y el empleo de la luz en la com- 
posición. Espigando en las obras de Rojas hemos seleccionado las que nos parecen más representativas en torno al manejo del espacio. El caso más interesante es, sin duda, Lo que quería ver el Marqués de Villena. Realmente podría considerarse una obra ejemplar para estudiar este tema en el autor puesto que acumula los más queridos y utilizados en del resto de su obra. Ya A. Farell ${ }^{17}$ puso de relieve el valor del tiempo y del espacio en esta comedia, considerada un pastiche para algunos ${ }^{18}$ y calificada por él, más acertadamente, como «deliciosa comedia de enredo y de magia». En ella se combinan y alternan prácticamente todos los recursos dramáticos utilizados por Rojas, como el ambiente estudiantil, el disfraz varonil de la mujer, la escenificación de una academia, elementos de magia, valores costumbristas, ambientes urbanos (casa, calles), cuevas, ríos, etc., sin olvidar un personaje noble y antiguo, como el marqués de Villena, integrado en el ambiente costumbrista según había enseñado el folklore. Unas veces se marca el tiempo real de la acción y otras se actualiza un pasado gracias a una narración que, a su vez, vivifica con la palabra un hecho ocurrido en el pasado y en un lugar distante del espacio escénico representado. Por si fuera poco, utiliza el motivo del espejo (en cuanto objeto mágico que anula distancias) y las cortinas para presentar a un mismo tiempo diferentes acciones ocurridas en lugares distintos y, gracias a la introducción del legendario marqués de Villena, asistimos a la fusión del tiempo y a las dos formas de magia, la negra, en la cueva de Fileno, y la blanca, o permitida, representada por el marqués.

\section{LA ALTERNANCIA DE ESPACIOS Y LA FUNCIÓN METATEATRAL PICTÓRICA Y CATÓPTRICA}

La primera jornada, que transcurre entre la Nochebuena y la Navidad, alterna el espacio abierto de las calles salmantinas y el cerrado de la casa de Serafina, con movimientos oscilantes entre dentro y fuera representado por los balcones y ventanas, para terminar en el escenario de la Academia, convertida en un auténtico teatro, como el resto de la casa de Serafina, en donde tienen lugar las confesiones íntimas, en gran parte reprimidas y ocultadas por el propio lenguaje. El planteamiento dramático se ejecuta a partir de juegos de oposición duales: dos grupos de estudiantes, dos candidatos a

17 Anthony J. FARELL, «Tiempo y espacio en Lo que quería ver el marqués de Villena», Espacio, tiempo y género en la comedia española. Actas de la II Jornadas de teatro Clásico (Toledo, 14-16 de noviembre, 2003), ed. de F. Pedraza, R. González Cañal y Gemma Gómez, Universidad de Castilla-La Mancha, Almagro, 2005, pp. 103-111.

18 Ann E. WiLtrout, «The Comedia as Pastiche: Rojas Zorrilla's Lo que quería ver el marqués de Villena», Los hallazgos de la lectura: estudio a Miguel Enguídanos, eds. de J. Crispín, E. Pupo-Walter y L. Lorenzo-Rivero, Madrid, Porra Tranzas, 1989, pp. 49-61. 
la cátedra, dos enamorados, dos mujeres que ocultan sus verdaderos sentimientos, y todo ello en perfecta correspondencia con una ubicación doble, abierta y cerrada.

El primer espacio real que aparece es una calle de Salamanca ${ }^{19}$, en tiempos del autor, de noche, concretamente en el día de Nochebuena (tiempo considerado como inhibidor de la magia ${ }^{20}$ ), y desde allí se evoca Madrid y diferentes lugares de Castilla la Mancha por parte de los estudiantes. En esa calle, aparece en un balcón Bermúdez (marcado doblemente en el texto: por la didascalia implícita, «a aquel balcón se ha asomado», y por la acotación Asómase don Pedro Bermúdez a la ventana), candidato de los estudiantes castellanos para obtener la cátedra frente a su opositor, el doctor Madrid, candidato de los manchegos. Según van andando y divirtiéndose por la calle salmantina, el gorrón Zambapalo describe, en estilo directo, las excelencias del rastro madrileño, en respuesta irónica a la afirmación de un estudiante de ser Madrid patria de grandes ingenios:

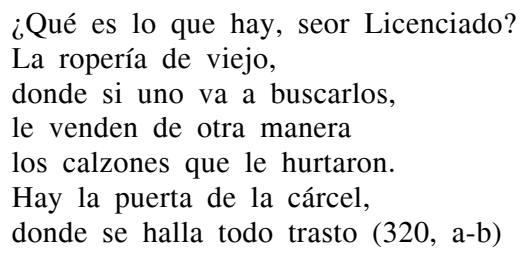

La larga retahíla nos muestra a un buen conocedor del barrio comercial más popular en la época en torno al Rastro y la plaza de Santa Cruz, en donde se ubicaba la cárcel, barrio caracterizado por el engaño y el robo, como se detalla en la información. No es baladí esta presencia de Madrid en el recuerdo puesto que doña Juana encubre su personalidad bajo el nombre del doctor Madrid.

Enseguida llegan los estudiantes ante la puerta de Serafina («Esperad, que hemos llegado/ de Serafina a la puerta», 320,b) a la que vitorean por su belleza. A la ventana se asoma su criada, Julia, avisándoles que su señora ya está en la cama y que les invita a asistir al día siguiente a una festiva Academia «de ciencias» en la que han de participar los licenciados. Entre peleas, elogios a sus ciudades respectivas y bromas, los estudiantes siguen su ruta nocturna hasta oír la voz de doña Juana quien, desde dentro, como señala la acotación, exclama « ¿Al Mercado», y es contestada por Bermúdez (también desde dentro) con la frase «Por la Rúa» $(321, b)$. Am-

${ }^{19}$ Cito por la edición de Mesonero Romanos, Madrid, BAE, 1952, pp. 319-348.

${ }^{20}$ Como resaltó Farell, no es casual situar la acción en este momento puesto que permite la confrontación entre magia negra y blanca. («Tiempo y espacio en Lo que quería ver el marqués de Villena», Espacio, tiempo y género en la comedia española, op. cit., p.104). 
bos salen a la calle (ella, vestida de estudiante, a la que se va a dirigir Bermúdez como don Alonso) y arengan a sus respectivos seguidores ( $\ll$ Señores manchegos, paso,/ que soy el doctor Madrid») para frenar sus peleas y citarse, al fin para la Academia de Serafina.

Por otra parte, y ya al día siguiente, Navidad, el marqués de Villena y su criado se dirigen a casa de Serafina. En este caso llaman a la puerta («iQuién es quien llama», 323,a) y le hacen entrar a una sala («en esotra sala entrad») en donde espera más de lo debido, según la disculpa de ella. Aquí, en el interior de la vivienda, a puerta cerrada, se entabla un diálogo por el que sabemos que él es el más sabio y está enamorado de ella sin ser correspondido. A continuación es conducido a otra sala cuando llega doña Juana, quien, a su vez, sostiene un diálogo neoplatónico sobre la belleza y el amor. Bermúdez, asimismo, es conducido a una tercera sala y en la casa se reúne al fin toda la Universidad. Tras ellos llega el mago Fileno y da comienzo el acto académico para el que se dispone un verdadero escenario, con una «silla sola, un bufete, unos músicos detrás» y «los estudiantes a los lados» $(324, \mathrm{c})$ como espectadores. Tras el acto, cuyos planteamientos iniciales van derivando gradualmente hasta concretarse en el amor como único objetivo («Dejad la Academia/ de ciencias e ingenios/ que se ha vuelto certamen de amor,/ y palestra de celos») el mago emplaza al marqués para que vaya al día siguiente a su casa si quiere comprobar sus poderes mágicos.

La segunda jornada se caracteriza por el predominio de la oscuridad de donde surgen, sin embargo, los mayores prodigios de dinamismo y teatralidad precisamente por la alternancia de luz y sombras, de espacios abiertos y cerrados, gracias a la magia. La jornada se inicia con la presentación de Zambapalo y el marqués ante la puerta de la cueva («esta la cueva ha de ser», 328,b) a la hora convenida. El estudiante muestra su miedo porque ya conoce la casa, de la que destaca su absoluta oscuridad y pobreza $\mathrm{y}$, pese a carecer de cualquier luz, la palabra, como si fuese una linterna, nos permite ver todo su interior:

Es larga como señor

de otros tiempos; es estrecha,

domo mercader de ahora,

y oscura como conciencia

de letrado [...]

Está en el zaguán la sala

y la alcoba en una pieza,

$\mathrm{y}$ aunque no hay cocina, es

todo el cuarto chimenea.

Hay en aquesta espelunca,

alcázar de la Noruega,

un lampiño, que desde el techo

de un cordel de lazo cuelga 
[...]

Sola la puerta es un ojo por donde un rayo aún no entra, y los que por otro salen, no salen bien si las cierran; raras son cuantas alhajas hay en su cuarto: una mesa como mula de alquiler que por puntos se derrienga; una silla de costillas, amarilla y aguileña, [...] un colchón que fue de lana, y ya es de hilas, pues si vieras la camilla de cordeles, aunque ninguno le aprieta, canta a cualquier movimiento, que es para dar mil denteras, no tienen polvo sus libros, pero como es la cueva tan húmeda, tiene lodo, ya podrida la madera. Un reloj tiene de vidrio que era de hora, cuando era, y habrá un siglo que no corre de enfermo de mal de arenas. Con un queso y con su pan pasa todo el año $(328$, b-c)

Fileno y Bermúdez, que ya estaban dentro de esta estancia casi mortuoria, con el tiempo detenido, salen a recibirles con «un candelero y una vela» y desde allí, los dos sabios tratan de utilizar la magia para resolver sus dudas. El primero en hacerlo es Bermúdez quien, para aliviar su mal de amores, cuenta cómo obtuvo la primera imagen que se grabó en su alma y desde entonces (tres años) no pudo quitársela. Hay que recordar el valor de la imagen grabada para definir el amor en la tradición occidental, fundamentada en el neoplatonismo, aristotelismo y la Biblia, como ya estudió G. Serès ${ }^{21}$ y que el teatro aprovechó extraordinariamente. Sin duda, esta imagen grabada en Bermúdez se corresponde con la importancia del arte para definir el amor (originada en la escuela de Florencia y recogida por León Hebreo en sus Diálogos de amor, en donde se refiere a cómo la imagen de la amada grabada en la mente provoca que el amante esté contemplándola siempre y desearla ${ }^{22}$.

Con un verbo de presentación («atended») consigue trasladar al auditorio desde el espacio oscuro, helado y lóbrego de la cueva, a un escenario

${ }^{21}$ La transformación de los amantes. Imágenes del amor desde al Antigüedad al Siglo de Oro, Barcelona, Crítica, 1996, especialmente pp. 50-53.

${ }_{22}$ Diálogos de amor, ed. de R. Reyes Cano, Barcelona, PPU, 1986, p. 326. 
absolutamente vivo, luminoso, ardiente y placentero sin salir de Salamanca. Frente al invierno escénico, se abre el escenario dramático del julio ardiente, del incendio de luz, de la espuma blanca del Tormes, del florido suelo y de la magia de una voz femenina a la que sigue hasta descubrirla en el agua desnuda, «toda dada al cristal líquido y bello» y «en ropa de cristal clavel hermoso» $(329, \mathrm{c}-330, \mathrm{a})$. En más de setenta versos nos ofrece un auténtico cronotopo de placer, con bañista desnuda incluida, que desaparece con otro espacio y tiempo de oscuridad, representado en este caso por el coche y su aliada, la noche. Teatralmente, la imagen de la mujer en la Naturaleza, en el agua, se corresponde con la pintura de visiones (Pereda, el Greco) cuya multiplicación de espacios también buscaba un efecto teatral, de acuerdo con las relaciones entre pintura y teatro, señaladas por Carducho. Basta recordar cómo el tratadista consideraba pintores a los dramaturgos y se refiere a sus «lienzos», tan vivos a veces que daban lugar a jugosas anécdotas entre los espectadores ${ }^{23}$.

Las formas del imperfecto enlazan las imágenes y el espacio pasado con el presente, al que se vuelve para que, por la magia, Bermúdez pueda saber si aquella imagen corresponde al ahora denominado doctor Madrid. De nuevo se insiste en la noche y, desde la cueva, Fileno les asegura que podrán ver cuanto quieran. El marqués, respondiendo al título de la obra, quiere ver lo que ocurre en la ciudad y para ello, como si se tratase de un escenario, «corre la cortina», «descúbrese un espejo», y «miran por él todo lo que va saliendo a representar» $(331, c)$. Sin duda, el espejo actúa aquí, simbólicamente, como una luz que da a conocer la realidad: primeramente, la actuación picaresca de tres estudiantes hambrientos en una calle oscura, y después la casa del doctor Madrid ante la que ven presentarse a Bermúdez acompañado de un criado de aquél, quien le esconde en un aposento al lado del cuarto de ella, y al mismo tiempo observa a Serafina, por petición del marqués.

Gracias al espejo se abren tres nuevos espacios, uno exterior (el de los estudiantes) primero, y dos cerrados, correspondientes a las dependencias de las mujeres. Se cierra el primero, se abandona el segundo, y se centra la acción en el tercer espacio, la casa de Serafina, en el momento en que está llamando doña Juana, vestida de estudiante (doctor Madrid). Con el equívoco provocado por la apariencia masculina y la ambigüedad del lenguaje amoroso en torno a los celos y al marqués, se vuelve otra vez al espacio interior en donde estaba oculto Bermúdez. Allí llega doña Juana y, bien cerradas todas las puertas, habla con su criado sobre su verdadera condición de mujer, ahora ya voluntariamente recuperada por su amor y celos. Descubierta por Bermúdez confiesa su identidad y le relata los por-

${ }^{23}$ V. CARducho, Diálogos de la pintura, ed. de F. Calvo Serraller, Madrid, Turner, 1979, p. 212. 
menores de su vida. La jornada finaliza con la vuelta al espacio de la cueva y la desaparición de todos los escenarios recreados gracias a un golpe del báculo de Fileno (llamada al sentido del oído más fuerte, con más valor en el siglo XVII que el de la vista para conocer la verdad). Lo conseguido en esta jornada es verdaderamente excepcional por el juego alternante de los espacios y la utilización de dos elementos más que sugeridores, la pintura y el espejo, además de la cortina que, en su movimiento alternante de correr y descorrer, asume la función de telón. Con estos motivos desarrolla verdaderos metateatros; primero, con el espacio exterior pictórico; después con el espejo, capaz de abrir teatros catóptricos, tan del gusto de Kircher y de la tradición óptica y mágica ${ }^{24}$.

La tercera jornada se inicia también en medio de la oscuridad («iNo hay luz? ¡Oh, qué oscuro está!», 338,b), correspondiente ahora a la casa de Cetina (criado del doctor Madrid despedido), a donde acude Julia, criada de Serafina, que ha sido igualmente despedida por esconder en su casa al marqués. Organizan una fiesta burlesca poniendo en solfa a los padres que no o envían nada a sus hijos y de pronto llama a la puerta el juez del estudio. Esconden a Julia debajo de un bufete y cuando se presenta el juez con Fileno, que busca a Cetina, la hace desaparecer por unos instantes para no ser descubierta. Quedan a la mañana siguiente en la posada del mago. Por su parte, ante la casa del marqués se encuentran Juana y Serafina, y por ellas sabemos que han pasado seis meses desde la última vez que se vieron. Cada una espera en una sala diferente y el marqués entabla una conversación con Serafina en la que descubre su identidad y elogia los méritos del marqués, aunque hace ver que su amor no es por él. Después, el marqués se enfrenta a Juana, y juntos deciden ir a casa de Serafina para aclarar definitivamente quién quiere a quien en ese juego de equívocos, pero antes Villena acude nuevamente a la cueva de Fileno, en donde espera Bermúdez para que le enseñe la magia el marqués. Entran después Cetina y Zambapalo y se cierra totalmente la cueva. El mago les advierte que en su pacto con la magia ha de dejar todos los años un esclavo y echan a suertes (con unas cédulas que introducen en un demoníaco cántaro negro) correspondiéndole al marqués quedarse. Utilizando su magia oscurece el día y confunde a Fileno quien introduce por error a Zambapalo en la cueva y enseguida es liberado por el marqués. Así, la magia natural termina con la diabólica y hace sucumbir bajo la tierra a Fileno. Al amanecer del día siguiente, de nuevo se halla Zambapalo en la calle de Serafina y quiere entrar en su casa. Todos se reúnen en ella y al fin, por los enredos creados y los fingimientos, todos quedan desengañados. Si en la primera jornada, la luz servía para introducir la atracción de la belleza, en ésta, el amanecer re-

${ }^{24}$ Ver Jurgis Baltrusaitis, El espejo. Ensayo sobre una leyenda científica, Madrid, Miraguano-Polifemo, 1988. 
presenta la realidad, que lleva aparejada el desencanto como lección moral que se inflige cada uno a sí mismo.

La oscuridad, eje estructurador de la obra, en contraste con el título, representa la confusión en todos los niveles (instintivo, natural y mental) cuando se intenta ver en la oscuridad de las sombras o apariencias. De ahí también el consiguiente desengaño final que todos reciben. Los espacios tienen una calculada misión dramática y moralizadora, y la nocturnidad unida a la cueva intensifica el esfuerzo del hombre por conocer una verdad con los ojos de los sentidos (explícito en el título) que no se acompasan con los del alma. A todos deja descontentos este conocimiento porque en ninguno hay una confianza interna en aquello que buscan ${ }^{25}$. Pero, además, los espacios también sirven para graduar la acción y seleccionar a los personajes. Al principio, la calle salmantina, con el bullicio de jóvenes enfrentados, y la Academia en casa de Serafina ${ }^{26}$, resultan representaciones divertidas y animadas en las que participan gran número de personas. A medida que desaparecen los que podríamos considerar coros (la música, el bullicio) los protagonistas se van quedando solos hasta que al fin, de nuevo en casa de Serafina, cada uno recibe su propio castigo por no haber sabido ver.

Hay una calculada utilización dramática de los propios personajes. El espacio de la cueva, en donde se desarrolla la mayor parte de la acción (aunque desde allí haya constantes cambios y traslados a otros lugares y tiempos), escénica y dramáticamente, resulta un centro mágico en cuanto se accede desde él a un múltiple teatro de acciones y sentimientos que se van perfilando a medida que nos permite adentrarnos en cada espacio limitado y cerrado da las habitaciones domésticas en donde tienen lugar las confidencias y en donde se van utilizando, a su vez, espacios concretos más reducidos, como el bufete, que encierran también su propio secreto. Todo está interpretado en términos teatrales por lo que al final todo desaparece, incluso la propia cueva de Salamanca (legendaria por su carácter nigromántico y científico) y con ella la tradición de buscar por medios no naturales la explicación de fenómenos tan naturales como la magia de la

${ }_{25}$ M. T. Cattaneo atribuye el final, sin casamiento y sin muerte a una «recuperación contagiosa de la racionalidad» en donde, «cada uno reconoce la locura de sus amores, engaño lisonjero como una visión mágica y como ésta de fácil desvanecimiento», «Los desenlaces en el teatro de Rojas», Francisco de Rojas Zorrilla, poeta dramático. Actas de las XXII Jornadas de Teatro clásico (Almagro, 13-15 julio 1999) ed. de F. Pedraza, R. González Cañal y Elena Marcello, Almagro, Universidad de Castilla la Mancha, Festival de Almagro, 2000, pp. 39-53). La cita en p. 48. No creemos que sea tanto la locura de sus amores como el no haber permanecido fiel al ámbito estético de la visión femenina envuelta en luz (verdadera belleza, de donde procede el verdadero amor, según Ficino-Hebreo) lo que ocasiona el desengaño final de todos.

${ }^{26}$ Recordemos que tras diferentes temas expuestos, la música se había encargado de apuntar el amor como el auténtico objetivo de la Academia. 
belleza Por eso, lo único que permanece y se convierte en el verdadero objetivo que quiere ver el marqués de Villena es el amor verdadero, representado en la obra por la mujer contemplada en la ribera del río, único espacio luminoso, libre y abierto (en completa oposición a la oscuridad de la cueva) que puede expresar la verdad, belleza y liberación del alma, frente a la rigidez o limitación impuesta por lo urbano, lo cerrado, los disfraces y lo normativo ${ }^{27}$. Esa bañista envuelta en blancura resulta un enigma (platónico) que deja honda huella en Bermúdez, pero su transformación en hombre desencadena la confusión en todos. El juego de luces y sombras permite el final negativo pero aporta el verdadero sentido al título, en principio, chocante y extraño.

Desde luego, la representación de esta obra en un ambiente cortesano ${ }^{28}$ podría haber sido todo un espectáculo en la época pues ya contaba la escenografía con grandes adelantos para representar escenas perspectivistas, y máquinas o tramoyas para los dobles tablados, así como con una luminotecnia muy avanzada para conseguir los efectos ópticos desarrollados desde la cueva. Pero, por sí misma, también responde al teatro catóptrico que, en sus manifestaciones más concretas, como las anécdotas en torno al agua (espejo celeste) tan repetidas en Rojas y utilizadas constantemente por Calderón, responden a los experimentos teórico-teatrales de la época (teatro catóptrico polidíctico del jesuita A. Kircher y G. De la Porta) al tiempo que sugieren un sentido simbólico por el pensamiento neoplatónico que encierran. También en Los celos de Rodamonte aparece el espejo combinado con la cortina para fabricar encantamientos (en respuesta a la tradición popular de cubrir los espejos), como hace Laurino, cuando cubre el espejo y deja a oscuras el palacio hasta que Rodamonte la vuelve a poner y recupera la luz. Incluso la cortina sola es capaz de encubrir transformaciones, como hace la maga en Los encantos de Medea, para aparecerse a Jasón como Creusa.

Si en Lo que quería ver el marqués de Villena el espacio exterior y el interior se alternan en juegos de luces y sombras, otro ejemplo muy interesante conseguido desde los espacios interiores es el drama Casarse por vengarse, cuyo tema parece obedecer a un caso real ocurrido en Toledo, según Cotarelo ${ }^{29}$, y que fue llevado al teatro anteriormente por Lope $(E l$

${ }^{27} \mathrm{Al}$ igual que la acción se va concentrando en unos pocos personajes recuérdese que en la Academia, la Música había ido anotando diversos temas hasta desembocar en el principal, el amor.

${ }^{28}$ La presencia de diferentes tablados hizo pensar a Shergold que la obra fue concebida para representarse en un ambiente palaciego (SHERgOLD, N. D., A History of the Spanish Stage from Medieval Times until the End of the Seventeenth Century, Oxford, Clarendon, 1967, p. 273).

${ }^{29}$ En Obras de Lope de Vega, II, RAE, Madrid, Tipología de la Revista de Archivos, Bibliotecas y Museos, 1906, p. XV. 
toledano vengado), seguido de Tirso (El celoso prudente) y Calderón ( $A$ secreto agravio secreta venganza).

\section{LA ALTERNANCIA DE SILENCIO Y RUIDO EN TORNO AL MURO ROTO}

En esta obra hay una acumulación y reiteración de los recursos de enredo más habituales en la comedia áurea y uno de los más utilizados por Rojas, Calderón y Tirso, como es el de los puentes artificiales utilizados por los amantes para encontrarse (minas abandonadas, alacenas, pasadizos, tornos, casas con dos puertas, etc. ${ }^{30}$ ). La acción transcurre cerca de Palermo, entre una quinta o caserío, rodeado de una selva y jardín, y el palacio de Palermo («ir a Palermo esta noche,/ que pues media legua está/ desta humilde casería», 104,c ;«Puesto que no hay media legua/ de esta quinta hasta la corte», 111,c). Esta proximidad espacial de exteriores está relacionada con la contigüidad de los espacios interiores. La primera jornada se inicia con el elogio, por parte de los protagonistas (Blanca primero y después Enrique) de la «selva» (como dice la acotación inicial) o lugar lleno de vegetación, convertido en un auténtico paraíso natural:

Pardo risco de sauces coronado, alegre y fértil prado,

por quien aquella selva, esta ribera

todo el año es florida primavera $(103, a)$

en donde no faltan ninguno de los elementos propios del locus amoenus («arroyuelo sonoro», trasmutado en «vihuela de cristal con trastes de oro»; «arpadas y sonoras, dulces aves»; «flores con voz»; «árboles matizados de colores,/ verde murta, alta hiedra,/ humildes flores») en perfecta correspondencia con el amor que ambos muestran, según el repetido estribillo "Que a Enrique de Sicilia adoro»/ «Que a Blanca, fénix de Sicilia adoro». Tras la descripción de la selva, Blanca nos ofrece un cuadro de la quinta al tiempo que narra la historia de sus vidas unidas. El paisaje de luz y belleza se corresponde con la belleza de sus amores:

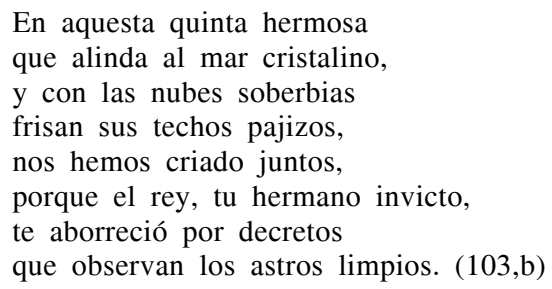

${ }^{30}$ GonZÁlez CAÑAl recoge un texto de Tirso en donde se resumen todas las posibilidades utilizadas en la comedia («Recursos espaciales del enredo en Rojas Zorrilla», Espacio, tiempo y género en la comedia española, op. cit . pp. 171-191). 
En este espacio natural, él fue acogido por el padre de Blanca y crecieron juntos, pero de tal modo estaban unidos que sus habitaciones, aunque contiguas, las convirtieron en una, estableciendo así un espacio interior único comunicado por dentro y con acceso por fuera desde el jardín, otro espacio fundamental para los amantes:

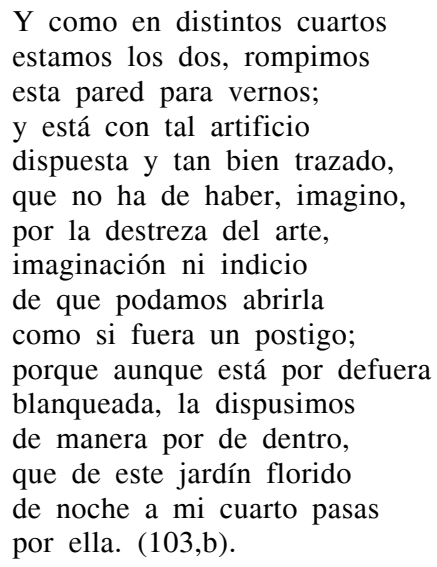

Las extensas comparaciones de sus sentimientos con la Naturaleza, especialmente con el arroyo, muestran la fragilidad de su situación puesto que el padre de ella no quiere darse cuenta de sus amores (conoce la diferencia entre él y ella y sabe que el testamento del hermano le obligará a casarse con otra). Muerto el hermano de Enrique, accede al trono y efectivamente ha de casarse con Rosaura rápidamente, según lo dispuesto por el rey. Tras este primera descripción del espacio, se presenta en otra escena al Condestable con Cuatrín, de camino al palacio de Palermo. Antes de llegar, el conde cuenta por qué está preocupado. La razón es la espera a la que le somete el padre de Blanca ante las nuevas circunstancias derivadas de la muerte repentina del rey. Mediante una narración en flash-back, introducida con las fórmulas habituales («cuéntame», «di el suceso»), el Conde nos informa de la primera vez que vio a Blanca, en un espacio de placer, auténtica pintura de color en donde el agua actúa de elemento luminoso o espejo que envuelve la belleza de la bañista desnuda:

Por la verde fragancia de este prado, matiz que dibujó la primavera por pintar de esmeralda esa ribera, llegaba yo a un arroyo cristalino $(105, \mathrm{c})$

Un guante en el agua (motivo erótico) le conduce al lugar en donde una mujer se está desnudando y la contempla oculto tras unas ramas. Esas ramas se comportan como telón de un nuevo escenario en donde el Conde 
es espectador directo que traslada por la palabra a su auditorio (Cuatrín y los espectadores del teatro) todo cuanto va observando. Sigue los pasos de esta mujer hasta descubrir que la mujer desnuda es Blanca. Su amor (imagen impresa grabada desde que la contempló) le lleva a pedirle al padre su mano y, aunque se la ha prometido, su tardanza en llegar ahora le desespera. Un fuerte ruido y alboroto (marcado por la acotación y el texto: «Ruido»; ¿Qué alboroto es aqueste?», 106,b) le devuelve, de la ilusión pictórica y el teatro mágico recreado, al escenario real de la entrada del palacio. Allí mismo Enrique se entera de que está obligado a casarse con Rosaura (sin posibilidad de evitarlo pues Blanca dejó sin firmar lo que debía ser su consentimiento y en su lugar lo firma Rosaura) y así lo hace en palacio, pero planea una pronta dispensación para casarse con Blanca, a la que piensa ver esa noche «por el roto secreto/ de la rompida pared» $(106, c)$ y contarle lo sucedido, al tiempo que el Conde le pide permiso para casarse con Blanca, ya que cuenta con el consentimiento del padre. A partir de aquí el enredo se acompaña de gran intensidad dramática: el padre decide casarla esa noche en la quinta («esta noche [..] la he de casar con el Conde/ en la quinta», 107,c; «en nuestra casería se haga la boda esta noche», 108,a ) y ella, sin poder evitarlo, culpa a Enrique de su situación y decide, respondiendo al título, casarse por vengarse. Si el día dejaba ver la quinta como un lugar idílico, de noche se convierte en el peor enemigo de la mujer.

La segunda jornada se inicia en el interior de la quinta. Ha sido la noche de bodas para ambos y Roberto y el Conde se encuentran «medio desnudos», «con las espadas desnudas» $(108, \mathrm{~b})$. «El conde con una luz en la mano» busca, desesperado por toda la casa, al causante de unos pasos que ha oído («siento en el retrete pasos», 109,a) y de una voz que llamaba a Blanca («iBlanca, Blanca!») y cree ver cómo alguien se esconde en una cuadra. Toda la casa se ha convertido en espacio de temor durante dos horas y cuando cree haber encontrado al intruso halla «los cuartos cerrados/ por de dentro con cerrojos» y «mi esposa sola en su cuarto», 109,a). El suegro le advierte que son «ilusiones de un encanto», y el silencio ${ }^{31}$ («peno, sufro, siento y callo», 109,a) intensifica la agonía del personaje al tiempo que produce en Blanca un presagio de tragedia sobre el que pende su fatal destino. El jardín de noche y con la llave en manos extrañas se ha convertido en el espacio dramático de recordado placer y asegurado disgusto, como expresa Blanca:

31 Es muy frecuente en Rojas, como en Calderón, la utilización del silencio como forma de interiorizar un drama. Recuérdese la cancioncilla que Calderón introdujo en varias obras a modo de leitmotiv simbólico (Los tres afectos de amor, Darlo todo y no dar nada, El encanto sin encanto y El mayor encanto amor): «solo el silencio/ testigo ha de ser de mi tormento», y que Moreto también utilizó en Industrias contra finezas. Aunque en Rojas no se cite la canción sí se utiliza su significado. 


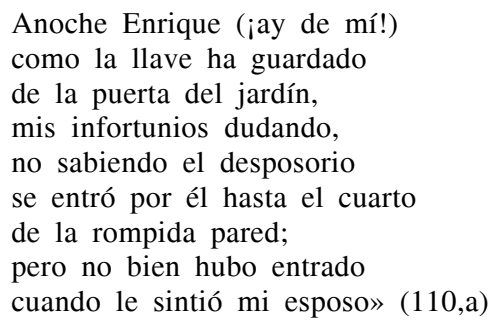

La vista del «prado ameno,/ fragrante alcázar de mayo» y la «copa en que la blanca aurora/ bebe aljófar destilado», le devuelve por unos momentos la tranquilidad y con ella trata de recuperar, solo fingidamente, la felicidad pasada pero enseguida desparece esa posible ilusión con la presencia de Enrique, quien, enfadado por el rápido casamiento del Conde y Blanca, le pide explicaciones. Enrique deja claro que la Reina está ajena a todo puesto que la ha dejado «en la nevada ribera/ a quien airado Neptuno/ con globos de espuma argenta» $(110, b)$ mientras él ha vuelto a la quinta en donde es criticado por Blanca por haberse atrevido la noche anterior a entrar «por la rota pared», al tiempo que le pide vaya al día siguiente a Palermo. Al llegar Rosaura, Enrique quiere evadirse sin ser visto por ella, que se queda muy extrañada de verle en «aquesta casería» $(111, a)$ y después de «haber andado esta noche /fatigando la maleza» $(111, c)$, precisamente en su noche de bodas. El silencio del Conde se corresponde con un itinerario interior. En solitario y para sí mismo realiza de nuevo el recorrido de las acciones ocurridas en la noche anterior. A la luz de cuanto va conociendo por el propio Enrique trata de desentrañar el significado de todo cuanto oyó y vio. De nuevo, al anochecer, y cuando está fuera el Conde, el jardín vuelve a convertirse en espacio de temor; primero por la dudosa situación de la puerta, entre abierta y cerrada («Señora, el Rey ha llegado/ por la puerta del jardín»; «se ha quedado abierta/ del jardín la puerta verde», «a cerrar voy», 113,a), y después, porque en los reproches que le hace Blanca, se une al jardín que él abre (con una llave que ya no le corresponde), su entrada por el muro roto, que tampoco le corresponde ya porque si fue medio y símbolo de comunicación ${ }^{32}$ y entrega de los amantes, ya no tiene ninguna función. Así, jardín y muro abierto han dejado de ser espacios de felicidad para representar dolor y desengaño:

\footnotetext{
Enrique, rey de Sicilia, monarca el más poderos$$
\text { [...] }
$$

Ya que arrojado te induzcas, te precipites furioso
}

${ }^{32}$ El muro roto equivale a la mina en Calderón. Sobre este tema véase el comprensivo y detallado trabajo de E. RULL, «El camino de la mina, vehículo de emociones en Calderón», Revista de Literatura, LXIV (128), 2002, pp. 385-411. 


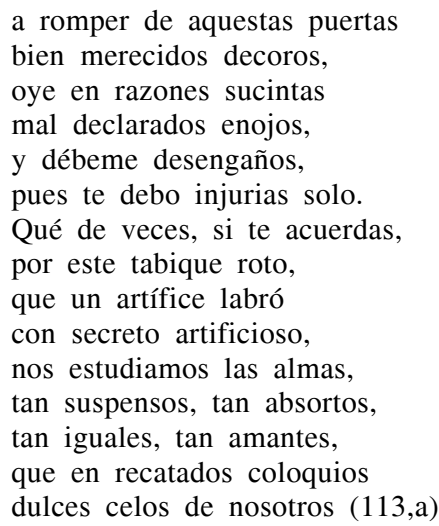

A medida que recuerda se acrecienta el dolor de Blanca hasta el punto de querer suicidarse en el mar («me diera infausto sepulcro/ en su centro cavernoso») y Enrique no puede impedir que se queme la mano con la vela (como señala la acotación) como despecho de haber sido tocada por él. En su excitación no oye un ruido (de golpe como de persona que salta) ni ve que Enrique se marcha («yo me aparto/ por este jardín frondoso,/ cuya llave traigo aquí», 113,b) y en su lugar aparece su marido, el Conde, quien así se entera del aborrecimiento que le tiene. Para salvar su honor cierra todo (cierra por fuera las puertas y vase) y sale («sin duda se fue / por el jardín,/ receloso/ o airado de mis razones», 114,a) dejándola sin posibilidad de escapar («Mas si está cerrado todo,/¿cómo saldré a esotra cuadra?»). Entonces es cuando para salvarse recurre al muro: «Mas por el tabique roto,/ pues no he tenido lugar, /para cerrarle/ me arrojo»). La acotación informa del estado del tabique, adelantando el final trágico: Ha de haber un tabique hecho de madera y dado de cal por encima, que se abra, y después a su tiempo se caiga todo, y encima de él ha de haber algunas pinturas. Abre Blanca el tabique y vase, 114,a). Por su parte, el Conde, después de haber cerrado todo abre la puerta del cuarto donde dejó a Blanca, sin encontrarla. De nuevo sus dudas se corresponden con la alternancia abrir-cerrar de puertas («Qué es esto?/ [...] ¿Yo no he cerrado? [...] Quiero/ mirar si del alboroto/ dejé las puertas abiertas;/ cerradas están; no topo/ a mis discursos salida,/ pues tener llave es impropio,/ que hoy he echado llaves nuevas/ a esas puertas», 114,a-b), a lo que se añade una inesperada llamada («Llaman a la puerta»; «Cielos, llamaron; yo quiero/ abrir») y Roberto le dice que ha llegado de Palermo y ha encontrado «en esta primera cuadra» a Blanca llorando. Para el Conde, la quinta ya se ha convertido en un lugar encantado: «iMas que me ha de volver loco/ esta quinta», 114,b).

En esta jornada, la casa, como lugar cerrado, desencadena una tensión extraordinaria, intensificada por la noche, el jardín y el puente entre las habitaciones. Cada personaje sufre en silencio sus propios temores, cada 
vez más profundos hasta llegar a la enajenación personal. Él se vuelve loco por no poder controlar el cierre de todo; ella, por no encontrar una salida por donde salvar su vida, que ve en peligro inminente. Los golpes (llamadas) hacen aún más evidentes los motivos de ese temor puesto que no dejan dudas sobre su realidad.

La tercera jornada se inicia, sin embargo, al amanecer («Cuando apenas el alba ha esclarecido»), y nos presenta a Blanca dirigiéndose al cuarto de su padre con una llamada («llamar quiero a su cuarto cuidadosa»; Llama Blanca; «Roberto: ¿Quién a estas horas cuidadoso llama?», 115,a). Al contarle lo ocurrido, vuelven a actualizarse los espacios del temor, con las puertas cerradas y la búsqueda de una salida («salgo a otra cuadra, déjame cerrada,/ temo perder la honra con la vida;/ acuérdome que tengo otra salida [...] Requiere las ventanas y las puertas; ciérralas todas», 115,c) pero el Conde, que escucha una voz del exterior (del campo), acude a la llamada. Es el momento que ella aprovecha para ir con su padre y pedirle que la oculte («Que me ocultes/ en tu cuarto, señor; que me sepultes/ donde airado mi esposo no me halle;/ que me escondas, en fin», 116,a). Al ruido (otra vez) de gente, ella se esconde y, cuando el padre cree que es el conde quien llega, encuentra a Enrique que, alterado, pide que cierren la puerta («esa puerta cerrad», 115,b) para relatar su historia sin ser oído. Aunque dice que estaba cazando y ha llegado al oír los gritos de ella, por los apartes sabemos que permaneció en la quinta («Disimular importa, que escondido/ en la quinta he escuchado aqueste ruido» 115 ,b) y al oír las voces salió al campo y llamó al conde («intentando provocarle/ de la quinta salí para llamarle/ con la llave que guardo», 115,c), para concertar lo que debía ser un duelo «en la ribera» y le pidió que le esperase «en la selva», para ganar tiempo y acceder así a la quinta. Sin embargo, no ha conseguido engañar al conde, que vuelve a la quinta, acompañado del criado Cuatrín. De nuevo, otra llamada, como advertencia decisiva («Llaman recio a una puerta de en medio») de la inevitable realidad anuncia la presencia el conde se extraña de ver todo cerrado («¿Cómo está aquí todo cerrado?»; «Ábranos presto»; «Abrid, Roberto»; «Abran o haráse el paso de la puerta», 116,c). Enrique también se esconde, por indicación de Roberto («Escóndese Enrique en el cuarto de Roberto y él abre la puerta», 117 ,a), pero Cuatrín le ha visto y ambos le siguen tropezándose con el suegro, a quien el conde cuenta cómo un hombre le sacó de la quinta «de la quinta me ha llevado,/ y sé que a la quinta misma/ se ha vuelto otra vez»). Pensando que el yerno empezaría a buscar en el cuarto de la hija, trata de sacar al rey de su habitación para que «no hallando al rey en mi cuadra» venza sus fantasías, pero Cuatrín se esconde tras una cortina mientras él duda por cuál cuarto empezar a buscar. Repara en la llave de una puerta («en la puerta se mira, si no me engaño, la llave/ puesta en la cerraja misma;/ bueno, cerraré esta cuadra,/ y ansí tendré prevenida, en vien- 
do la de Roberto, / esta también. Cierra la puerta de Blanca con llave», «cerrada está»; Encerrando va a entrar a la cuadra de Roberto 117,c) y se propone entrar primero en la habitación de Roberto. Hay un forcejeo, quiere entrar por fuerza y sale Enrique, quien inventa un problema de Estado y finge que está buscando a su hermano porque se siente traicionado: «tuve noticia/ que a mi hermano desde ayer/ tenéis oculto en la quinta, y que viene a conjurar/ lo más noble de Sicilia»; «aquesta noche os llevé/ a esa playa cristalina»; «volví, en fin, hallé a Roberto,/ díjele mis fantasías,/ allanóme a aquestas cuadras, / no halle a nadie y ya salía», 118,a). Las razones le convencen y se siente indigno de haber pensado mal de su esposa («Ya quiero ver a mi Blanca,/ que en mi pecho se eterniza»). Cuando la va a buscar observa que la «rota pared/ se está moviendo en sí misma» y que «la abren por de dentro». Se esconde y puede ver cómo sale «por el tabique» la criada de Blanca con un papel en la mano. Al ver todas las puertas cerradas, Silvia se había visto obligada también «a abrir la pared rompida» para buscar a Cuatrín y llevar un recado de Blanca al rey. El conde descubre entonces la traición y la razón de sus confusiones:

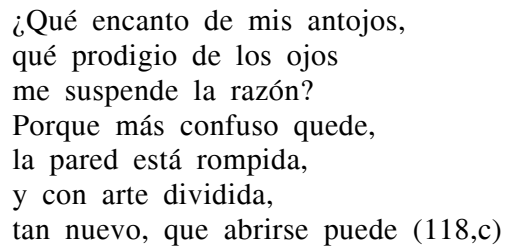

Por la nota entregada a Silvia conocemos que Blanca se ha casado por vengarse de Enrique, y mientras el conde ha «abierto las puertas todas» («y dispuesto en tiempo breve/ con su venganza mi dicha/ y en mi cautela su muerte, y ya el tabique he mirado», 119,c). El conde, disimulando, le pide a Blanca que escriba una nota al rey para que le exima ir a la guerra, al tiempo que piensa en el estado del tabique y lo que puede hacer con él («el tabique rompido/ cuidadoso he mirado y advertido:/ por la parte de en medio es de madera,/ y parece pared por la de fuera,/ con tan extraño arte,/ que se une por aquesta y la otra parte», 120,a). Considera que es culpable de su deshonra («¿Esta pared no derribó mi honra?») y justifica que sea, asimismo, el objeto de su reparación, y el arma del sacrificio. Tras dudarlo por unos instantes puede más su deseo de venganza, y para escarmiento, derriba el tabique entero a la parte de adentro con cuadros de pintura, $120, c)$. Después declara ante todos, incluido el rey, que, «sin saber de qué manera,/ o por antigua o por frágil/ se cayó aquesta pared/ sobre su rostro, tan grave,/ que al paso que la ha oprimido/ se ha traducido cadáver»; $A l$ zan la pared; vense debajo Blanca, muerta, y el recado de escribir caído allí junto», 120,c). 
Este mismo motivo del tabique roto lo utiliza Rojas en La traición busca el castigo, aunque aquí no constituye más que una referencia a la que alude Don García cuando le pide al donjuan Andrés que deje de seguir a su amada porque le está impidiendo que se fije en él a pesar de los heroicos esfuerzos que está haciendo, entre los cuales está la rotura del muro. Este muro abierto representa igualmente la comunicación constante de los amantes ( Y $\mathrm{Y}$ como solo un tabique/ de nuestras dos casa pone/ estorbos a nuestro amor,/ amor que imposibles rompe,/ por la frágil quebradura/ de una pared, permitióme/ tal vez su voz a mi oído/ tal mi llanto a sus temores» , 234,c). Por esa abertura no existe riesgo en sus citas («os trasladáis y decís/ las palabras una a una,/ los requiebros mil a mil», 241,b). Esta función se rompe cuando es descubierto el secreto y se vuelve enemigo cuando, como en Casarse por vengarse, se actúa, por error. El mismo significado de comunicación de almas aparece en otra obra, en El mejor amigo, el muerto (durante la jornada segunda, escrita por Rojas) por lo que sus diferentes funciones coinciden con el sentido polivalente que ya había aplicado Calderón al motivo, como estudió Rull, y cuyas conclusiones podrían aplicarse igualmente al uso que le da Rojas, aunque su peculiaridad sea no profundizar en cada caso pero sí dejarlo sugerido. Así, si los caminos de la mina calderoniana «se abren a múltiples significaciones, a incesantes sugerencias, que van de lo cómico a lo trágico, de la condena a la salvación, de la prisión a la libertad y de ésta a la responsabilidad o al destino» ${ }^{33}$, el muro roto tiene la misma función que la mina. En las palabras de reproche que dirige la reina a Roberto, advirtiéndole que está tratando de asaltar la fortaleza de su belleza, puede verse la identidad de mina y tabique roto: «Más allá es abrir la mina/ del alma; el amor constante/ es el ingeniero; a ruegos/ y a merecimientos se abre» ${ }^{34}$. El contenido espiritual y amoroso que representa ese muro en Casarse por vengarse, en principio positivo, intensificado por el espacio de placer del jardín y la quinta, propicio para la belleza, el placer y la felicidad compartida, se convierte en camino laberíntico y dinámico. El muro entonces asume un sentido negativo y moralizador porque se ha interrumpido la comunicación, se ha impuesto el silencio y en su lugar ha triunfado la soledad y el dolor, representado por esa caída y desmoronamiento final en donde, incluso las pinturas que adornaban a la vez que ocultaban, se desintegran.

Esa múltiple función del tabique roto lo expresa igualmente el abrir y cerrar de puertas. Como la mina o el muro abierto, representa la alternancia de luz y oscuridad, y la libertad o la opresión. De ahí el interés del autor en este tipo de motivos que remiten a un espacio polivalente en donde lo teatral se funde con lo simbólico para conseguir una completa estrategia

${ }^{33}$ E. Rull, «El camino de la mina», op. cit. p. 410.

${ }^{34}$ El mejor amigo, el muerto, en Obras completas de Calderón, ed. de Astrana Marín, Madrid, Aguilar, 1941, p. 1351,a. 
dramática que incorpora lo simbólico, lo visual y lo auditivo al arte escénico. Por ello, los mismos espacios pueden funcionar cómicamente en una comedia de enredo o asumir funciones dramáticas, como ocurre con el jardín o las puertas de la casa en Casarse por vengarse. En todos los casos, Rojas nos ofrece un calculado desarrollo plástico y dramático con el que orienta a los espectadores, sin dar tregua al dinamismo alternante de sucesos y espacios. 